\title{
New SMA Short Fibers for Cement Composites Manufactured by Cold Drawing
}

\author{
Eunsoo Choi ${ }^{1}$, Dong Joo Kim ${ }^{2}$, Chanyeong Jeon ${ }^{1}$ \& Seungmin Gin ${ }^{1}$ \\ ${ }^{1}$ Department of Civil Engineering, Hongik University, Seoul, Korea \\ ${ }^{2}$ Department of Civil and Environmental Engineering, Sejong University, Seoul, Korea \\ Correspondence: Eunsoo Choi, Department of Civil Engineering, Hongik University, Seoul 04066, Korea. Tel: \\ 82-2-320-3060. E-mail: eunsoochoi@hongik.ac.kr
}

\author{
Received: January 17, 2016 Accepted: February 1, 2016 Online Published: February 5, 2016 \\ doi:10.5539/jmsr.v5n2p74 URL: http://dx.doi.org/10.5539/jmsr.v5n2p74
}

\begin{abstract}
This study suggests new shape memory alloy reinforcing fibers manufactured by cold drawing method. This study prepares NiTi shape memory alloy (SMA) wires with diameter of $1.0 \mathrm{~mm}$. Then, the wires are elongated by cold drawing and, thus, the diameters are reduced to 0.93 or $0.965 \mathrm{~mm}$, respectively. This procedure introduces prestrain into the wires. When elongated SMA wires are heated, the shape memory effect is activated; this process recovers the deformed length as well as the reduced diameter due to Poisson's effect. Cold drawn wires with diameters of 0.93 and $0.965 \mathrm{~mm}$ recover diameters of 0.018 and $0.024 \mathrm{~mm}$, respectively, with heating. The bulging of the SMA fiber in the radial direction inside cement composites induces confining pressure around the fiber and increases bond strength. When an SMA fiber is heated at the both ends, the heated parts bulge and the fiber shape looks like a dog-bone. Such a dog-bone shaped fiber can provide a geometrical anchoring action that also increases the bond resistance of the fiber. This study conducts pullout tests of SMA fibers to understand their pullout behavior and assess bond stress. The heated fibers and dog-bone shaped fibers increase pullout force compared to those of as-received and cold-drawn fibers. When dog-bone shaped fibers are heated, they show twice the pullout force of dog-bone shaped fibers without heating because geometric anchoring action as well as additional frictional resistance due to confining pressure are activated.
\end{abstract}

Keywords: SMA fibers, shape memory effect, bond resistance, cold drawing, cement composites

\section{Introduction}

Shape memory alloys (SMAs) are smart materials that have received high attention in aerospace, mechanical, and medical engineering fields. Particularly, in the last two decades, applications of SMAs in civil engineering have increased year by year; these applications include seismic isolation (Dolce et al., 2000; Sharabash \& Andrawes, 2010; Ozbulut \& Hurlebaus, 2010; Choi et al., 2005) or retrofit devices (DesRoches \& Delemont, 2002), energy dissipation devices (Yang et al., 2010), devices for the prestressing of concrete (Sawaguchi et al., 2006; Maji \& Negret, 1998), and smart cement composites (Krstulovic-Opara \& Naaman, 2000; Shajil et al., 2013). SMAs show unique properties of shape memory effect (SME) and superelasticity (SE) (Janke et al., 2005); both are useful characteristics for buildings and civil structures. Martensitic SMAs that exhibit the shape memory effect are used for energy dissipation or for the prestressing of concrete. Superelasticity contributes to provide a self-centering capacity (Choi et al., 2010a) or self-healing of concrete (Song et al., 2006). For these purposes, several types of SMAs such as bars, cables, or wires have been used. In particular, SMA wires have been widely used for various targets in civil engineering: such as confining or prestressing of concrete, seismic isolation devices, or reinforcing fibers of cement composites.

For reinforced concrete beams, SMA bars or strands were used to produce a prestressing force or to conduct crack-curing using the SME. Researchers usually used electronic resistance to heat SMAs in order to induce the SME and, thus, SMA bars or strands should be extended outside the concrete in order to allow the connection of electronic power cables (Li et al., 2008); however, this is not practical. To overcome this problem, Choi et al. (2011) suggested the use of the hydration heat of concrete to activate the SME of SMAs embedded in concrete.

SMA fibers in cement composites increase the weak tensile strength of conventional concrete or mortar and thus control cracking these materials. Employment of SMA fibers in cement composites provides several advantages. 
SMA fibers are appropriate for thin-walled structures and members with various geometries such as plates, shells, and arcs, where long SMA bars or wires are not applicable. After Maji and Negret (Maji \& Negret, 1998) who firstly used strands of wires to introduce prestress into a concrete plate, it appears that Krstulovic-Opara and his colleagues (Krstulovic-Opara \& Naaman, 2000) first introduced a concept to induce self-stressing using SMA fibers into cement composites. They used long NiTi SMA fibers, showing the self-stressing capacity of cement composites through experimental tests. Moser et al. (2005) introduced loop and star shaped SMA fibers to provide a geometrical anchorage; they also used the shape memory effect of prestrained SMA wires to provide prestressing stress that prohibited tensile cracking in mortar. However, loop or star shaped SMA fibers are difficult to use for mass production and may induce a mixing problem that prevents uniform distribution of fibers in cement composites and that is observed in steel reinforcing fibers with end hooks; this problem is called "fiber balls". Shajil et al. (2013) used pseudoelastic NiTi SMA fibers, in austenitic phase, to provide self-centering capacity to a cement mortar member subjected to cyclic loading. They used end-hooked fibers and indicated that the major bond arose from the end anchorage at the hooked ends. If an SMA is in pseudoelastic phase, it is very difficult to bend it into an end-hooked shape because the SMA recovers the deformation. Thus, in this case, the end-hooked shape is made under martensitic phase and, then, an annealing process is needed to transfer it to the austenitic phase. This process may increase the cost of production, and researchers may have the problem of fiber balls, as well.

To avoid the problem of fiber balls, straight-shaped SMA fibers are required. However, when using such fibers, the bond resistance of the fibers will be relatively low because only chemical and low frictional bonds work between straight SMA fibers and cement composites; chemical bonding is very low for practical uses of fibers. Therefore, a major aim of this study is to provide SMA fibers with straight shapes, in order to avoid the fiber ball problem; this study also suggests a method of increasing the bond resistance of straight SMA fibers. For these purposes, this study performs pullout tests of single SMA fibers in cement composite.

\section{SMA Fibers without End-Hooks}

It is well known that a prestrained SMA wire in martensitic phase recovers its elongated length due to the SME.

The SME phenomenon is well explained in Figure 1(a) using a stress-strain-temperature diagram in three dimensions (Choi et al., 2008). An SMA is deformed under martensitic phase (I), and then unloaded (II) followed by heating them above the temperature $\mathrm{A}_{\mathrm{f}}(\mathrm{III})$, which is a temperature to complete austenite transformation. Then, the alloy recovers it original shape. Pre-elongated martensitic SMAs with deformation-restraint induce recovery stress by heating up above transformation temperature but lose some level of stress by cooling (see Figure 1(b)); the remaining stress can be used for post-tensioning or prestressing forces. The recover and residual stress highly depends on the alloy composition, manufacturing process, and strain of pre-elongation (Shin \& Andrawes, 2010; Choi et al, 2010b; Saleeb et al, 2015a; Saleeb et al., 2015b).

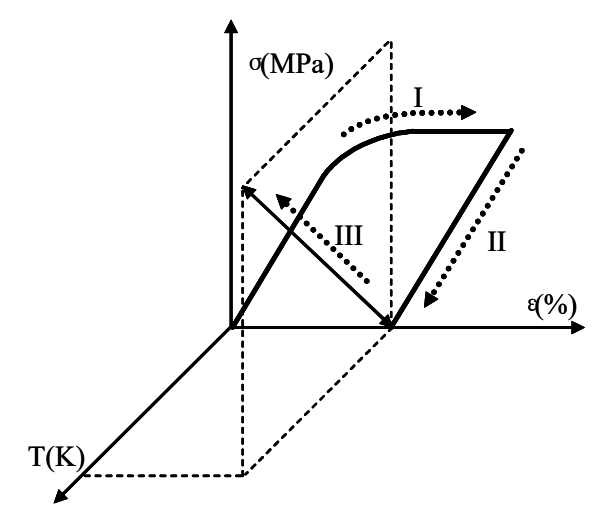

(a) Stress-strain-temperature diagram in 3D

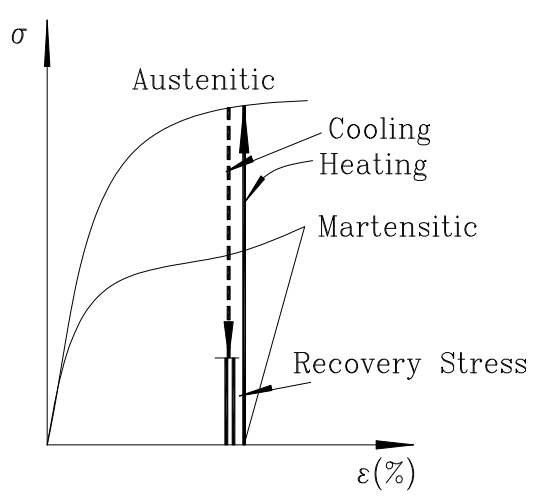

(b) Recovery and residual stress

Figure 1. Diagram for recovery and residual stress due to shape memory effect (Choi et al., 2008)

An elongated SMA wire shows a reduction of diameter or thickness due to the Poisson effect. During the SME procedure, the reduced diameter or thickness of a wire is also recovered because of the Poisson effect. When a prestrained SMA fiber is embedded in cement composite, the bulge of the SMA fiber in the radial direction induces confining pressure around the fiber since the bulge is restrained by the cement composite; . This confinement 
contributes to increase the bond resistance of the SMA fiber due to increased. Figure 2(a) demonstrates a new concept for straight SMA fibers. Another type of straight SMA fibers has a dog-bone shape in Figure 2(b). If only the end parts of a prestrained SMA fiber are heated to induce the SME, then the end parts bulge and the shape of the fiber looks like a dog-bone. A dog-bone shaped SMA fiber can provide anchoring resistance in cement composite. If a dog-bone shaped SMA fiber in cement composite is heated, then the fiber has anchoring resistance as well as additional confining pressure and, thus, obtains bond resistance higher than can be obtained using a single application of heating on an SMA fiber or dog-bone shaped SMA fiber.

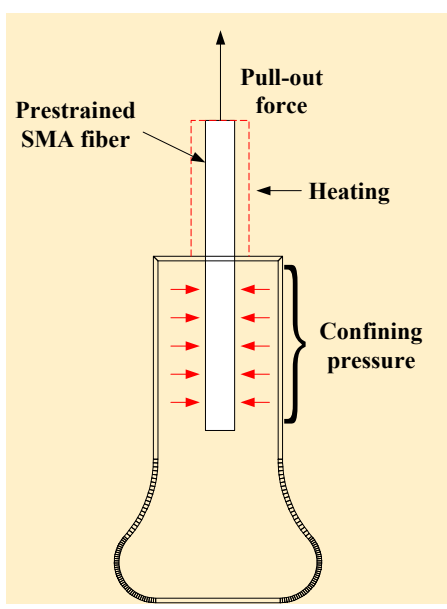

(a) Straight fiber

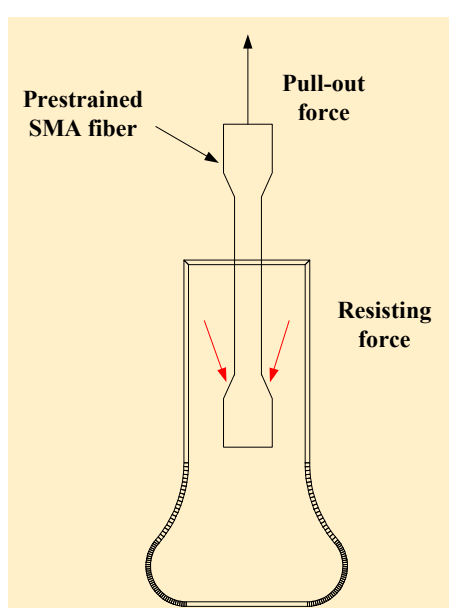

(b) Dog-bone shaped fiber

Figure 2. Conceptual drawing of new straight SMA fibers

\section{Thickness Recovery of Cold-Drawn SMA Fibers}

This study used three types of SMA fibers to measure thickness recovery of elongated SMA fibers; two types of fibers were elongated by cold-drawing method, and so was the last one by a direct tensioning method. First, this study prepared SMA wires of $\mathrm{Ni}_{50.47}-\mathrm{Ti}_{49.53}$ (at. \%) with a $1.0 \mathrm{~mm}$ diameter. The transformation temperatures of the as-received SMA material measured by DSC (Differential Scanning Calorimetry) were as follows: $\mathrm{M}_{\mathrm{s}}=31.3^{\circ} \mathrm{C}, \mathrm{M}_{\mathrm{f}}$ $=5.4^{\circ} \mathrm{C}, \mathrm{A}_{\mathrm{s}}=48.2^{\circ} \mathrm{C}$, and $\mathrm{A}_{\mathrm{f}}=60.5^{\circ} \mathrm{C}$ (see Figure 3(a)). To induce the SME on the wires, prestrain had to be introduced. This study tried two methods of cold-drawing, which was conducted using a die, and direct tension using a tensile device. Through cold-drawing, the diameters of the SMA wires were reduced to 0.93 or $0.965 \mathrm{~mm}$. The degree of cold-work is defined as the percent reduction in the wire cross-sectional area; the degrees for the two drawn wires are $13.5 \%$ and $6.88 \%$, respectively. The drawing stress increases with increasing of the degree of cold-work and, thus, three or two iterations of die-drawings were used for the 0.93 and $0.965 \mathrm{~mm}$ diameter samples, respectively. Dies with diameters of $0.97,0.95$, and $0.92 \mathrm{~mm}$ were subsequently used to fabricate $0.93 \mathrm{~mm}$ wires; the first two dies were applied for the $0.965 \mathrm{~mm}$ wires. The cold-drawn SMA material of $0.93 \mathrm{~mm}$ diameter did not show any detectable transformation peaks in the temperature range considered (see Figure 3(b)). However, a subtle R-phase transformation was observed at the temperature close to the clear R-phase peak in the as-received material. Tensile behaviors of the two cold-drawn wires were compared with that of the as-received $1.0 \mathrm{~mm}$ wire shown in Figure 4. The as-received wire showed a typical tensile behavior of martensitic SMAs such as low stress plateau and elastic and then plastic deformation. The martensitic plateau finished at approximately $6 \%$ strain. The cold-drawn SMA wire showed only deformation of plastic flow, and the stress-induced transformation disappeared; this was observed in previous study (Gall et al., 2008). This behavior was caused by the material of a complicated dislocated mixture and residual martnesite produced during the cold drawing work. Secant Young's moduli at $0.3 \%$ strain were estimated as 390 and $440 \mathrm{MPa}$ for the 0.93 and $0.965 \mathrm{~mm}$ wires, respectively; these values were much larger than the corresponding modulus of $172 \mathrm{MPa}$ for the as-received SMA. 


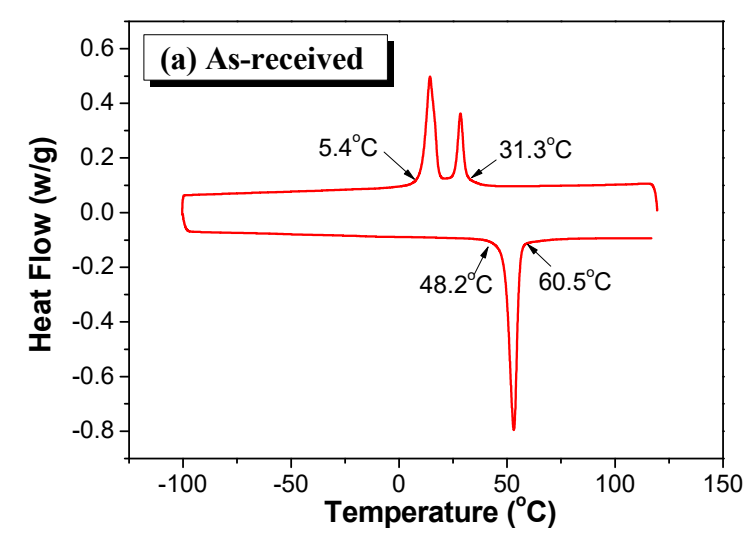

(a) As-received SMA wire with $1.0 \mathrm{~mm}$ diameter

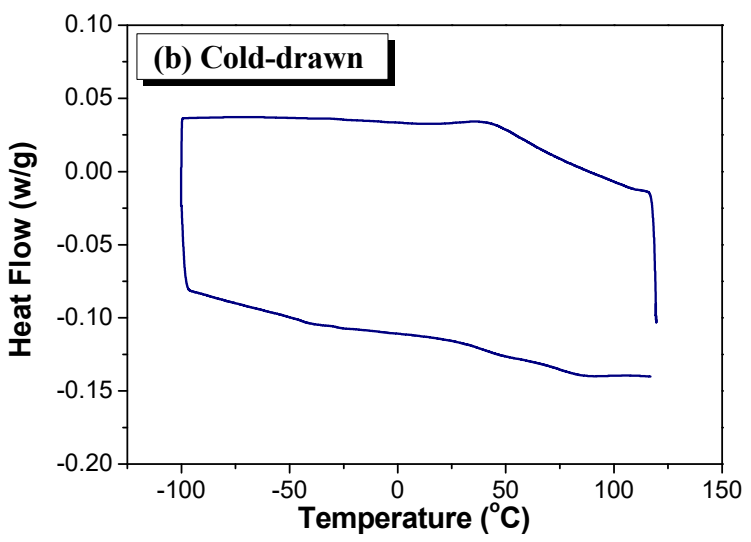

(b) Cold-drawn SMA wire with $0.93 \mathrm{~mm}$ diameter

Figure 3. DSC curves of $1.0 \mathrm{~mm}$ as-received and $0.93 \mathrm{~mm}$ cold-drawn SMA wires

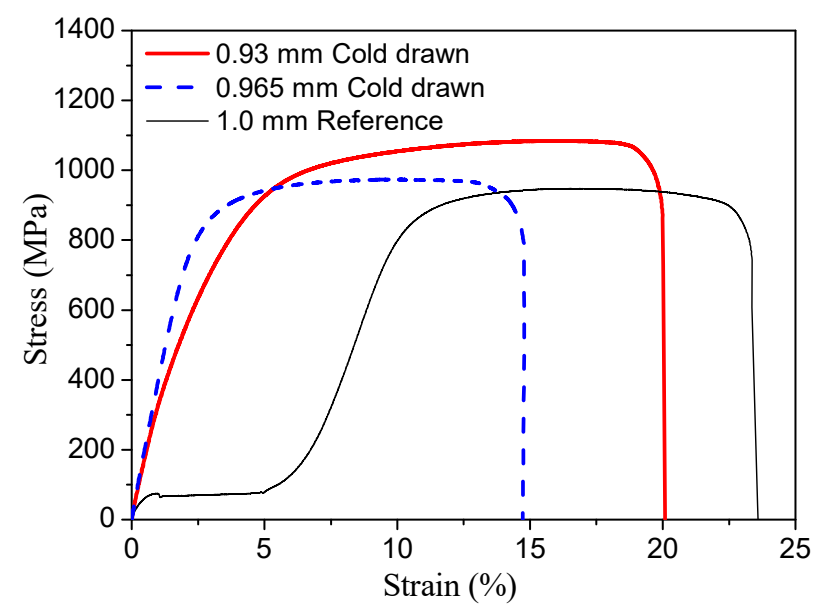

Figure 4. Monotonic tensile behavior of as-received and cold-drawn SMA wires

SMA fibers of $50 \mathrm{~mm}$ length were cut from the cold-drawn, then the cold-drawn SMA fibers were heated to induce the SME, and recovered diameter was measured. Four fibers were tested for each type of fiber and measurement of the diameter was conducted at five locations. Figure 5 shows the diameter recovery of the cold-drawn fibers due to the SME. The average diameter recoveries were 0.018 and $0.024 \mathrm{~mm}$ for the 0.93 and $0.965 \mathrm{~mm}$ wires, respectively. These diameter recoveries represented area recovery ratios of $3.38 \%$ and $4.69 \%$, respectively. For a direct tension, the $1.0 \mathrm{~mm}$ SMA wire was elongated to $7.0 \%$ strain to introduce prestrain. In this case, the wire recovered $0.477 \%$ strain, and $6.523 \%$ strain remained. The average reduction of diameter was $0.027 \mathrm{~mm}$ companying with the area reduction ratio of $5.33 \%$. Thus, the final diameter was $0.973 \mathrm{~mm}$. By heating, the deformed diameter of $0.027 \mathrm{~mm}$ was perfectly recovered; this means that the reduced all area of $5.33 \%$ was recovered. Table 1 shows summary of diameter recovery tests of the cold-drawn and direct tensioned SMA wires. The cold-drawn SMA fibers recovered only partial amount of reduced diameter; the 0.93 and $0.965 \mathrm{~mm}$ cold-drawn fiber recovered $25.7 \%$ and $68.6 \%$ of deformed diameter, respectively. Thus, the two cold-drawn SMA fibers remained unrecovered area of $10.12 \%$ and $2.19 \%$, respectively, although the direct tensioned SMA fiber recovered all reduced diameter and deformed area. The unrecovered diameter of the cold-drawn SMA fibers is caused from the plastic deformation during the cold drawing, which is not recovered by heating. The results also indicate that more amount of cold drawing of SMA fibers does not guarantee more diameter recovery of the fibers.

Figure 6 shows the recovery stress of the three prestrained SMA wires due to temperature variation during the heating process. In the figure, the ' $\mathrm{CD}$ ' and 'DT' represented cold-drawing and direct tension, respectively. The developed maximum stresses of the cold-drawn wires were 224 and $358 \mathrm{MPa}$ for 0.93 and $0.965 \mathrm{~mm}$ wires, respectively; these values were smaller than the corresponding value of $512 \mathrm{MPa}$ for the direct tensioned wire. When the finishing temperature approached approximately $20^{\circ} \mathrm{C}$, the three recovery stresses became almost zero. 
In general, the recovery stress of NiTi SMAs decreases with decreasing temperature, and it becomes zero below the $\mathrm{M}_{\mathrm{s}}$ temperature (Choi et al., 2010c). It appears that larger recovery stress of the direct tensioned fiber is related to more diameter recovery. As mentioned above, the cold-drawn fibers did not produce relatively large recovery stress because of the plastic deformation. The recovery stress of the SMA fiber is important since it contributes to close cracks in concrete structures. More bulging in diameter of the SMA fibers can produce more confining pressure in cement composites, which can further increase bond resistance. Thus, the direct tensioned SMA fiber may be more effective than the cold-drawn fibers. However, the cold-drawn SMA fibers showed SME and bulging in diameter. Thus, the cold drawing method is valid to introduce prestrain into SMA fibers. Observing the experimental results, it can be seen that more area reduction due to cold drawing did not lead to more area recovery. Thus, in the future, this process should be studied to find an optimum area reduction ratio for cold drawing.
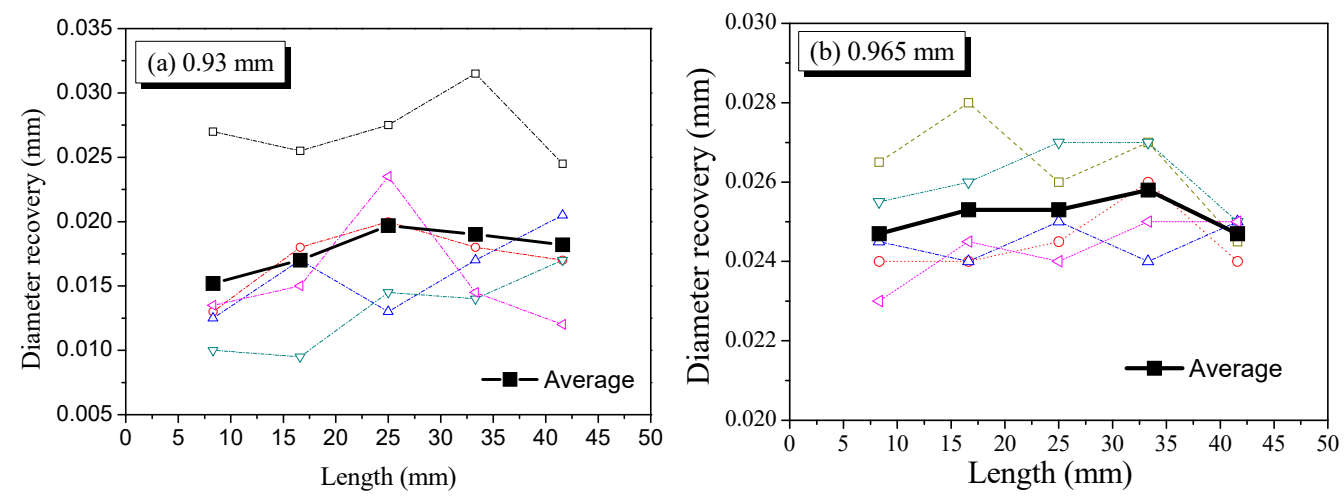

Figure 5. Diameter-recovery of the cold-drawn SMA wires

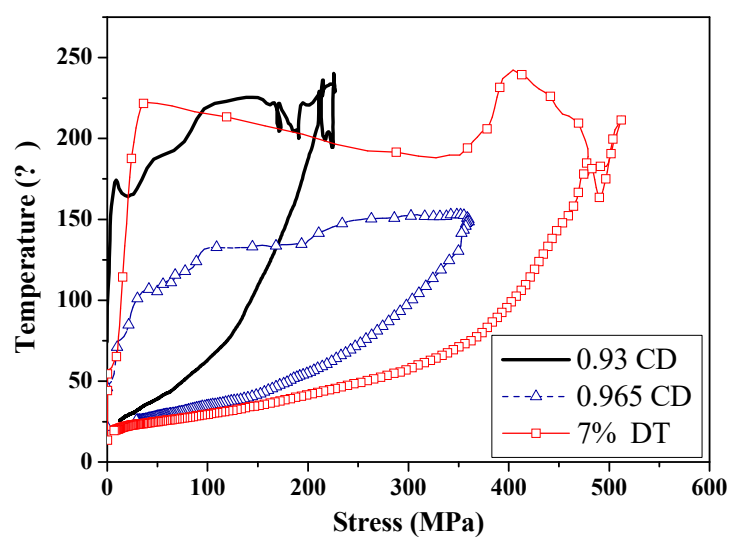

Figure 6. Recovery stress of prestrained SMA wires due to temperature variation

Table 1. Summary of diameter recovery tests of SMA fibers

\begin{tabular}{cccc}
\hline Fiber type & $\begin{array}{c}\text { Cold-drawn } \\
0.93 \mathrm{~mm}\end{array}$ & $\begin{array}{c}\text { Cold-drawn } \\
0.965 \mathrm{~mm}\end{array}$ & $\begin{array}{c}\text { Direct tension } \\
\text { 7\% strain }\end{array}$ \\
\hline Initial diameter $(\mathrm{mm})$ & 1.0 & 1.0 & 1.0 \\
Final diameter $(\mathrm{mm})$ & 0.93 & 0.965 & 0.973 \\
Reduced diameter $(\mathrm{mm})$ & 0.07 & 0.035 & 0.027 \\
Area reduction ratio $(\%)$ & 13.5 & 6.88 & 5.33 \\
Recovered diameter $(\mathrm{mm})$ & 0.018 & 0.024 & 0.027 \\
Recovery ratio of diameter $(\%)$ & 25.7 & 68.6 & 100.0 \\
Diameter after heating $(\mathrm{mm})$ & 0.948 & 0.989 & 1 \\
Area recovery ratio $(\%)$ & 3.38 & 4.69 & 5.33 \\
\hline
\end{tabular}




\section{Pull-Out Tests}

This study used a series of direct pullout tests to assess the bond behavior of SMA fibers manufactured by cold-drawing. In the tests, the $0.93 \mathrm{~mm}$ cold-drawn SMA fibers were used, and their results were compared with that of the $1.0 \mathrm{~mm}$ as-received SMA fiber. There were three types of specimens with straight fibers and two types of specimens with dog-bone shaped fibers. Thus, total five types of specimens are illustrated in Table 2.

Table 2. Test program of pull-out tests of SMA fibers

\begin{tabular}{llllll}
\hline Type & Shape & $\begin{array}{l}\text { Diameter } \\
(\mathrm{mm})\end{array}$ & $\begin{array}{l}\text { Bulging length } \\
\text { at both ends }\end{array}$ & $\begin{array}{l}\text { Embedded length } \\
(\mathrm{mm})\end{array}$ & $\begin{array}{l}\text { Heating after } \\
\text { embedment }\end{array}$ \\
\hline SF-1.0 & Prismatic & 1.0 & 0 & 15 & Non \\
SF-0.93 & Prismatic & 0.93 & 0 & 15 & Non \\
SF-0.93H & Prismatic & 0.93 & 0 & 15 & Heating \\
SF-0.93D & Dog-bone & $0.93 / 0.945$ & $5 \mathrm{~mm}$ & 15 & Non \\
SF-0.93DH & Dog-bone & $0.93 / 0.945$ & $5 \mathrm{~mm}$ & 15 & Heating \\
\hline
\end{tabular}

\subsection{Specimens and Test Set-Up}

The length of the fibers was $30 \mathrm{~mm}$, and $15 \mathrm{~mm}$ of the total length was embedded in mortar. There were two shapes of SMA fibers, as prismatic and dog-bone shape. The dog-bone shaped SMA fibers were heated at both ends in air, and the bulged length of the dog-bone shaped SMA fibers was $5 \mathrm{~mm}$. After heating, the heated fibers were quenched into water to decrease the temperature, and then the bulged diameter was measured. Thus, the bulging effect due to high temperature disappeared, and the average bulged diameter was $0.945 \mathrm{~mm}$; the heated portion bulged and, thus, its shape looked like a dog-bone. For the prismatic fibers, there were three types of fibers: 1) SF-1.0 of as-received SMA fiber with $1.0 \mathrm{~mm}$ diameter, 2) SF-0.93 of cold-drawn SMA fiber with $0.93 \mathrm{~mm}$ diameter, and 3) SF-0.93H of cold-drawn SMA fiber with $0.93 \mathrm{~mm}$ diameter; this specimens were heated inside an oven after embedding the fiber. For the dog-bone shaped fibers, there were two types of SF-0.93D and SF- $0.93 \mathrm{DH}$ specimens. The dog-bond shaped fibers of the SF-0.93DH specimens were heated after embedding. The SF- $0.93 \mathrm{H}$ and SF- $0.93 \mathrm{DH}$ specimens were placed in an oven at $110^{\circ} \mathrm{C}$ temperature for 24 hours, and, then, they were cooled to room temperature. It appears that this heating process induced state transformation of the embedded SMA fibers in mortar since the heating for 24 hours was sufficient to increase the temperature of the embedded fibers up to $110^{\circ} \mathrm{C}$. When the SMA fibers of the SF- $0.93 \mathrm{H}$ and SF- $0.93 \mathrm{DH}$ specimens were heated, the heating process was expected to generate lateral confining pressure around the fibers due to the bulging.

This study used mortar to embed the SMA fibers, and its compressive strength was $28 \mathrm{MPa}$. Figure 7 provides an illustration of a mold that was used to manufacture 10 specimens at once; the figure also shows a complete specimen. A length of $15 \mathrm{~mm}$ was extruded for the pullout test. Figure 8 shows the setup for direct pullout test of a single fiber. Each specimen was gripped with a half-circular holder; the fiber was pulled out using an actuator. Displacement control of $1.0 \mathrm{~mm} / \mathrm{min}$. was used for the tests, and pullout force and displacement were measured by a load cell and a displacement transducer installed in the device. Five specimens were tested for each case.

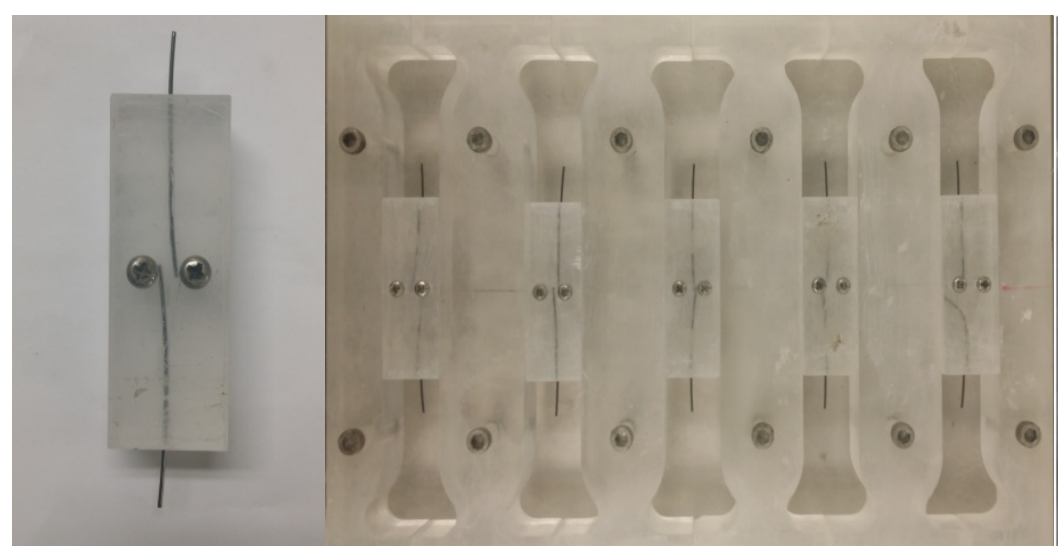

(a) (b)

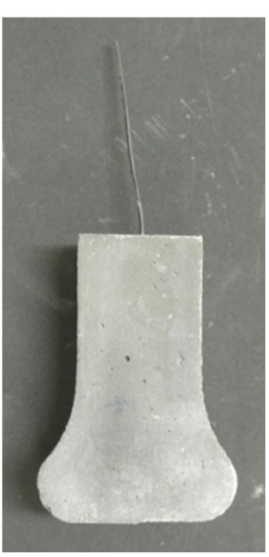

(c)

Figure 7. Mold and specimen: (a) device to hold fibers; (b) Mold to cure mortar; (c) picture of a specimen 


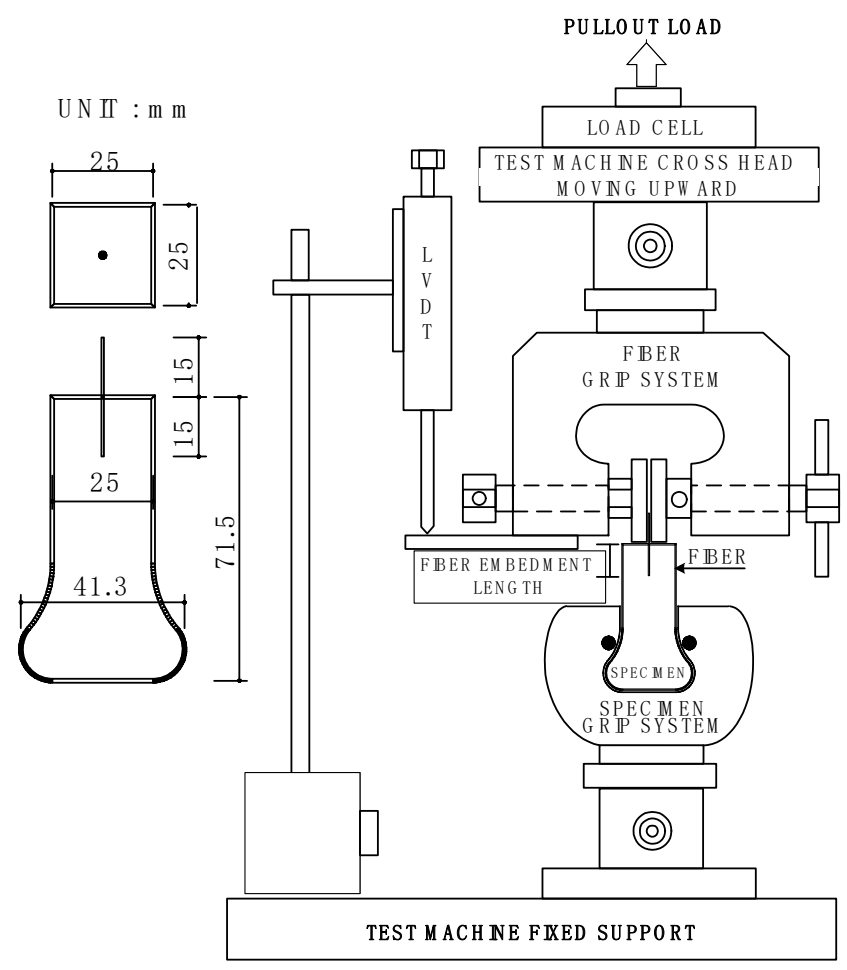

Figure 8. Test setup for pullout test of single fiber

\subsection{Experimental Results and Discussions}

The relationship of pullout force and slip for the SMA fibers is shown in Figure 9, in which average curves also are provided. Figure 10 compares the average pullout forces of the fibers. The pullout stress in the graphs was the stress in a fiber developed by the pullout force, which was calculated by dividing the pullout force by the cross-sectional area of the fiber. From the measured pullout force and slip of the fiber, bond stress of a fiber $\tau_{b}$ can be calculated using the following equation (Choi et al., 2010d):

$$
\tau_{b}(x)=P(x) /\left[\pi d_{f} L_{f}(x)\right]
$$

where, $P(x)$ and $L_{f}(x)$ are the pullout force and the embedded length of fiber according to the slip, and $d_{f}$ is the diameter of the fiber. Bond stress around a fiber provides information of shear stress in mortar contacting the fiber; thus, estimation of bond stress is meaningful. The equation (1) is valid only for the prismatic fibers. For the dog-bone shaped fibers, the diameter difference was $1.9 \%$ between the bulged and non-bulged cross-sections. Thus, in this study, it is assumed that bond stress around the dog-bone shaped fiber is distributed evenly along the length. Figure 11 shows the bond stresses of the fibers calculated using the average pullout forces. The bond stress consists of three contributions, including: (1) chemical adhesion, (2) frictional resistance, and (3) anchoring action. Thus, bond stress can be expressed as shown below:

$$
\tau_{b}=\tau_{\text {adh. }}+(2 \mu / \pi) \sigma_{n}+\tau_{\text {anch. }}
$$

where, $\mu$ and $\sigma_{n}$ are the frictional coefficient and the normal confining pressure. The dog-bone shaped fibers provided anchoring action at the end part, which is not distributed uniformly along the length of a fiber. However, for comparing between the prismatic and dog-bone shaped fibers, it is assumed in this study that bond stresses of all fibers are distributed uniformly along the length. Bond stresses developed at the maximum pullout force $P_{\max }$ are illustrated with the corresponding slips in Table 3; the bond stress was called peak bond stress after this. The bond stress of the fibers increased until the first slip; in this region, the chemical bond and friction were working together. After the bond-slip, for the prismatic fibers, the chemical bond disappeared, and only the friction remained; in this state, the bond stress remained flat since the friction was stable. However, for the dog-bone shaped fibers, the bond stress after the first slip increased continuously till almost the end of the fibers because of anchoring action due to the bulged portion of the fibers. When the embedded length was almost ended, the bond stress for all fibers increased high and was dropped abruptly 
Table 3. Pullout force, bond stress, and the corresponding slips of SMA fibers

\begin{tabular}{cccc}
\hline Specimen & Slip $(\mathrm{mm})$ & Bond stress (MPa) & Pullout force (N) \\
\hline SF-1.0 & 0.159 & 0.544 & 25.3 \\
SF-0.93 & 0.188 & 0.650 & 30.2 \\
SF-0.93H & 0.163 & 1.075 & 50.1 \\
SF-0.93D & 0.125 & 1.062 & 49.6 \\
SF-0.93DH 1 ${ }^{\text {st }}$ slip & 0.139 & 1.509 & 65.5 \\
SF-0.93DH 2 ${ }^{\text {nd }}$ slip & 3.50 & 3.501 & 118.1 \\
\hline
\end{tabular}
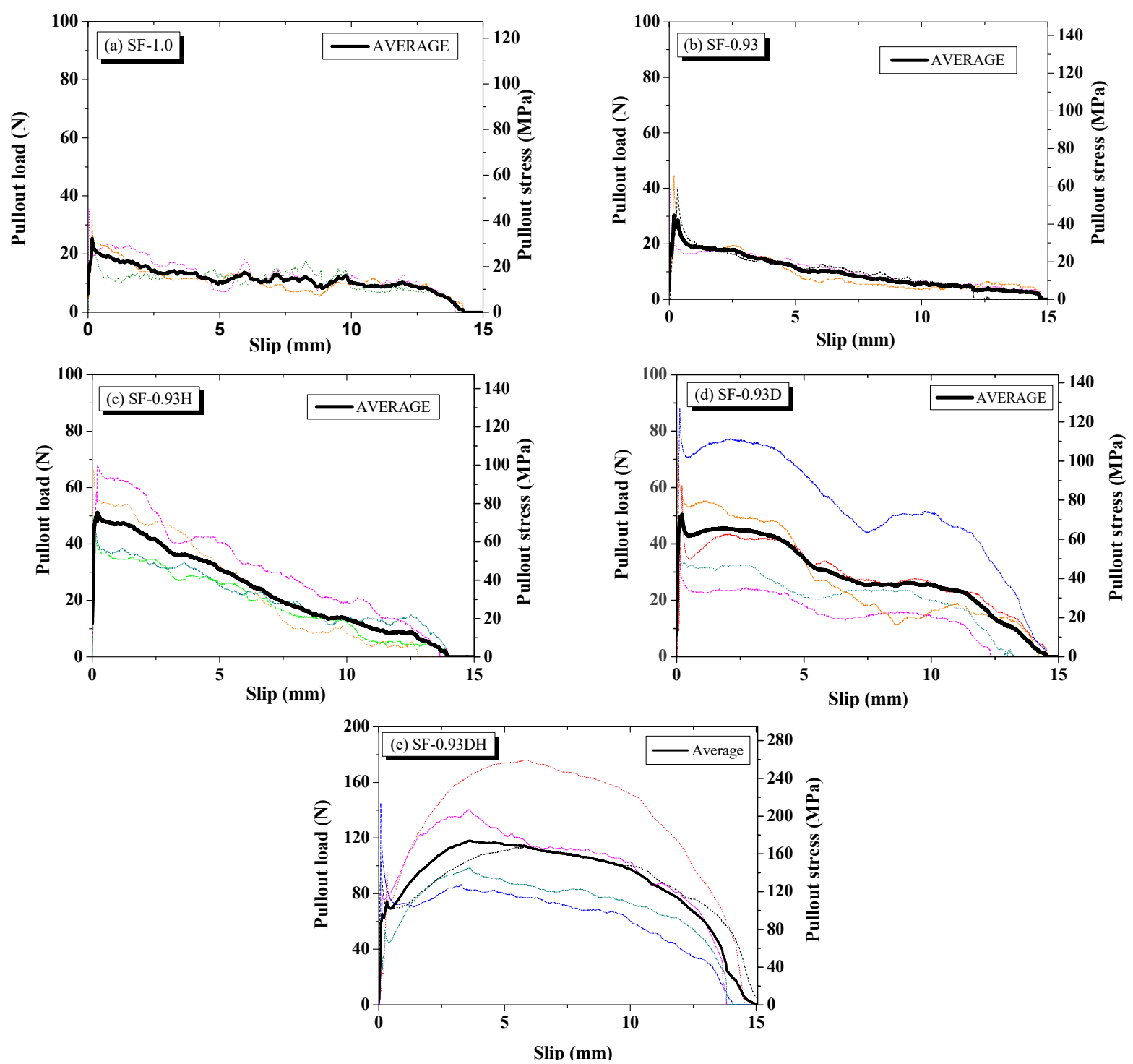

Figure 9. Five test results and their average of pull-out tests of the SMA fibers

\subsubsection{SF-1.0 Versus SF-0.93 Fibers}

The comparison of the above two fibers illustrates the influence of the cold drawing on the SMA fibers. SF-1.0 and SF-0.93 fibers have a prismatic cross-section and, thus, they do not have any end anchoring resistance. Only the chemical adhesion and frictional resistance in Equation (2) contribute to increase the pullout force or bond stress. The average peak bond stress of the SF-0.93 fibers was estimated at $0.65 \mathrm{MPa}$, which was 1.2 times larger than $0.544 \mathrm{MPa}$ of the SF-1.0 fibers. The chemical adhesion and frictional resistance work together until bond-slip; 
however, after bond-slip, only frictional resistance remains, and bond stress becomes constant in the region. In Figure 11(a), the two fibers in the frictional resistance region can be seen to have almost the same bond stress; this indicates that the frictional forces of the two fibers were equal. The frictional force highly depends on the surface condition of the fibers. Therefore, it is concluded that the cold-drawing process did not significantly change the surface condition of the fibers. The difference of peak bond stress between the two fibers therefore must be caused from chemical adhesion. The fibers under tension showed lateral reduction in diameter due to Poisson's effect. This necking phenomenon may contribute to disconnect the chemical adhesion of the fiber. In Figure 4, the initial Young's moduli of the as-received and cold-drawn wires were 172 and $390 \mathrm{MPa}$, respectively. Thus, the lateral strain of the SF-1.0 fiber is 2.27 times larger than that of the SF-0.93 fiber at the identical pullout stress. In addition, the area-reduction of the SF-1.0 fiber is 5.14 times larger than that of the SF-0.93 fiber. This larger area reduction appears to contribute by leading to earlier bond-slip in the SF-1.0 fiber.
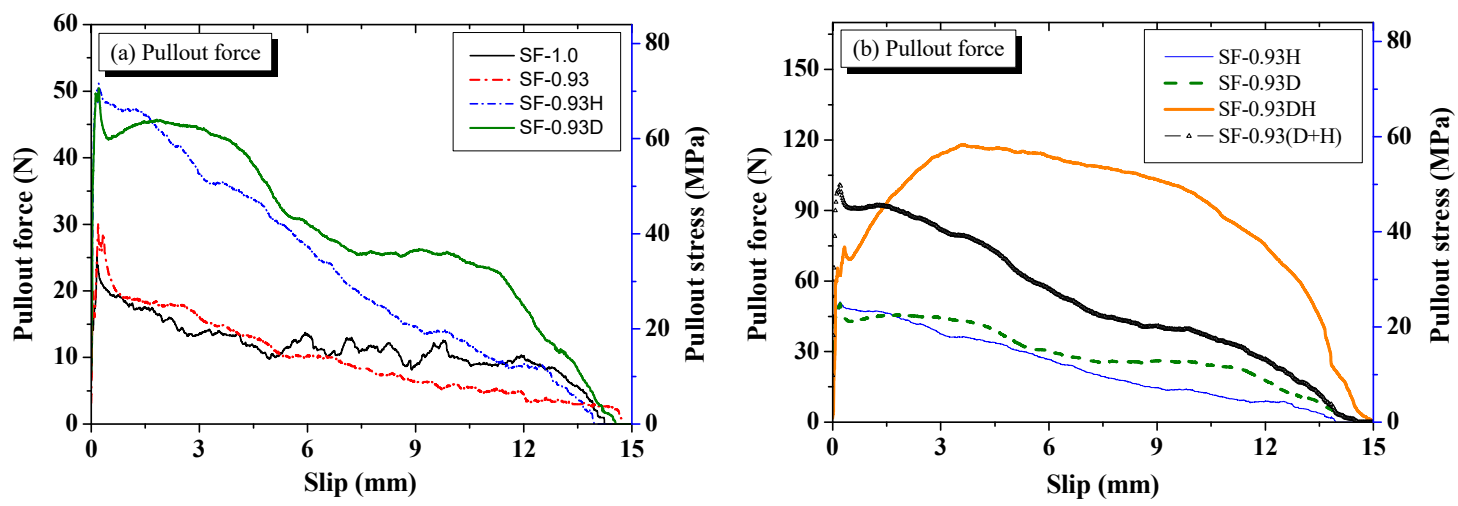

Figure 10. Comparison of the results of the pull-out tests
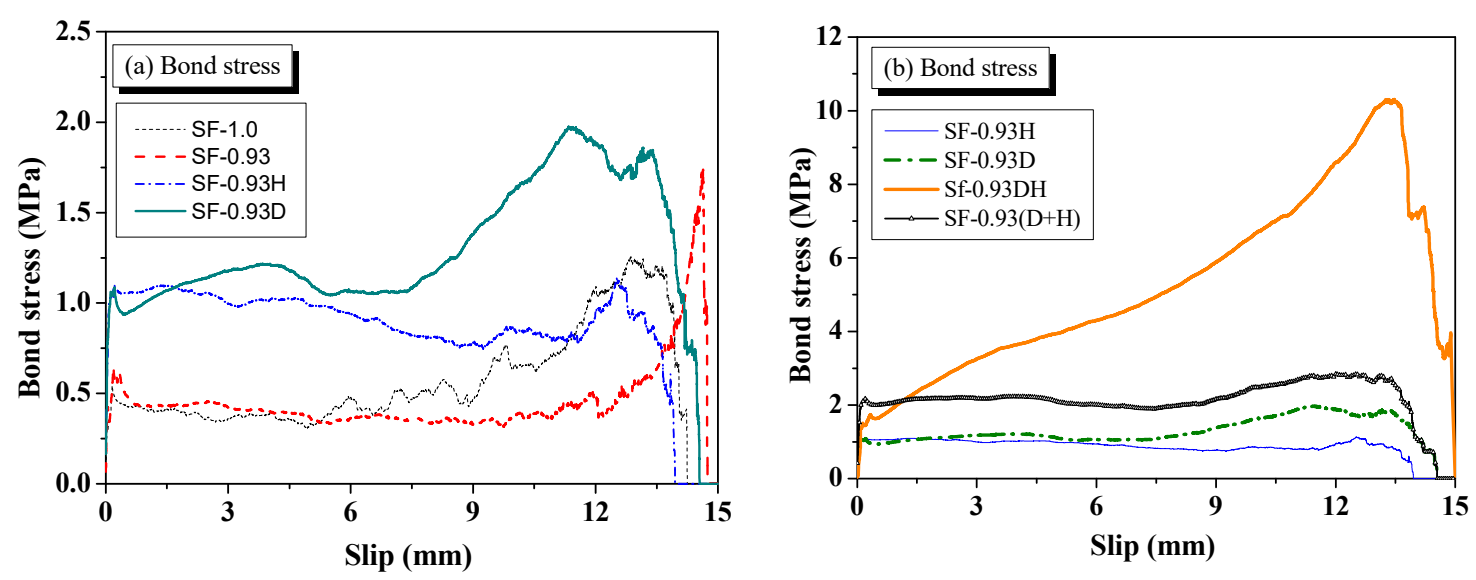

Figure 11. Bond stresses of the SMA fibers

\subsubsection{SF-0.93 Versus SF-0.93H Fibers}

This comparison explains how the shape memory effect works on increasing bond resistance of the SMA fibers. The SF-0.93H fiber embedded in the mortar was heated to induce the shape memory effect, which produced the bulging of the fiber. However, the bulging of the fiber was constrained by the mortar. This increased confining pressure around the fiber and, thus, the second term of frictional resistance in Equation (2) also increased. After the bond-slip, the two fibers showed almost constant friction. The measured bond stresses at the slip of $0.8 \mathrm{~mm}$ are 0.433 and $1.058 \mathrm{MPa}$ for the SF-0.93 and SF-0.93H fibers, respectively; so, the difference was $0.625 \mathrm{MPa}$, which was caused purely by increased confining effect. Thus, the increment of the bond stress $\Delta \tau_{b}$ can be used to assess the increased confining pressure $\Delta \sigma_{n}$ using the following equation $\Delta \tau_{b}=(2 \mu / \pi) \Delta \sigma_{n}$. The frictional coefficient between the SMA fiber and mortar depends on the surface condition of the SMA fiber and strength of the mortar, and the measured value is not suggested yet. Rabbat and Russell (1985) suggested a 
coefficient of static friction between steel plate and concrete as 0.57 for dry interface. It is considered that the frictional coefficient could be adopted to estimate the increased confining pressure since the surface condition of the steel plate was similar to that of the SMA fiber. The estimated increasing confining pressure was estimated as $1.72 \mathrm{MPa}$, which was purely due to the bulging of the fiber.

\subsubsection{SF-0.93H Versus SF-0.93D Fibers}

The SF-0.93D fiber provided anchoring action due to geometric discontinuity at the end parts and increased the pullout force or bond resistance; thus, the third term in Equation (2) is activated. In this section, the effect on bond of the anchoring action of the dog-bone parts will be compared with that of increased confining pressure in the SF-0.93H fibers. The peak bond stress of the SF-0.93D fiber was $1.09 \mathrm{MPa}$, which is almost identical to that of the SF-0.93H fiber. After bond-slip, the SF-0.93D fiber showed hardening behavior in bond stress while the SF-0.93H fiber released stable bond stress. In addition, the SF-0.93D fiber showed a second period of hardening behavior from the slip of $8 \mathrm{~mm}$. After bond-slip, the SF-0.93D fiber showed a plateau of pullout force until approximately 5 $\mathrm{mm}$; this means that anchoring action was the main resistance in the region. The anchoring action was stable regardless of the embedded length of the fiber. If frictional resistance is primarily in effect, the pullout force should be reduced with increasing pullout length. After this plateau, the pullout force decreased and, then, a second plateau of pullout force appeared. This means that the fiber provided another anchoring action in the second region. The two plateaus generated the hardening behavior of bond stress; this behavior was totally different from that of the $\mathrm{SF}-0.93 \mathrm{H}$ fiber, for which friction was the primary resistance and the bond stress decreased continuously after bond-slip.

\subsubsection{SF-0.93DH Fibers}

The SF-0.93DH fiber provided additional frictional resistance due to the shape memory effect as well as geometric anchoring action at the end parts. Thus, in Equation (2), the second and third terms are activated. The pullout behavior of the SF-0.93DH fiber was totally different from that of the SF- $0.93 \mathrm{H}$ or SF- $0.93 \mathrm{D}$ fibers. The SF-0.93DH fiber showed a continuous increment of pullout force till the slip of $3.6 \mathrm{~mm}$ after the first bond-slip of $0.33 \mathrm{~mm}$. The dog-bone shaped fiber of the SF-0.93D also showed hardening behavior after the bond-slip due to the anchoring action, and stable or small degradation of pullout force was observed before sudden dropping of the force. The hardening behavior with pulling out the fiber was totally due to the anchoring action since frictional resistance should decreased with pulling out the fiber. The increment of pullout force in the SF-0.93D fiber due to hardening was $2.6 \mathrm{~N}$ at the slip of $1.83 \mathrm{~mm}$, which was $5.2 \%$ of the maximum pullout force. However, the SF-0.93DH fiber increased $48.3 \mathrm{~N}$ of pullout force till the slip of $3.6 \mathrm{~mm}$, which was $41.0 \%$ of the maximum pullout force. This indicates that the heating process enhanced the anchoring action of the dog-bone parts of the fiber that provided relatively great increment of pullout force along with large slip. A soft degradation of pullout force was lasted till the slip of $10.0 \mathrm{~mm}$ before abrupt dropping of the pullout force. The pullout behavior of the SF-0.93DH was compared with the linear combination of the SF-0.93D and SF-0.93H fibers in Figure 10(b), which was noted as SF-0.93(D+H). This showed that the behavior of SF-0.93DH fiber was not a linear combination of the behavior of the two fibers. At the bond-slip, the SF-0.93DH fiber showed relatively small force compared with that of the SF-0.93(D+H) because total length of the fibers was relatively small. However, a strong anchoring action in the SF-0.93DH fiber overcame the first shortage after the bond-slip; it is considered that the anchoring action dominated the over whole behavior. In the SF-0.93D fiber, the anchoring action seems not to be dominant compared with the frictional resistance. Thus, the combination behavior of the two fibers decreased continuously after the bond-slip and was similar to a mixing two frictional resistances. The bond stress of the SF-0.93(D+H) in Figure 11(b) showed flat behavior after the bond-slip; this was a typical bond behavior due to frictional resistance. However, bond stress of the SF-0.93DH fiber increased continuously after the bond-slip; this was mainly caused by the anchoring resistance.

The reason of the anchoring domination in the SF-0.93DH fiber is not clear in this state and, thus a further study is required to understand this phenomenon. However, two conjectures are possible. The first one is that the increased confining pressure around the fiber by the bulging of the fiber due to the shape memory effect may interface to the dog-bone parts to generate dominant anchoring action. The second possible conjecture is that the exposure of the mortar to high temperature may affect on the anchoring action of the fiber; however, this conjecture is weak. If the mortar effects on the anchoring action, it should also do on the friction. However, the friction was not dominant in the SF-0.93DH fiber as mentioned above. Therefore, consequently, it appears that the dominant anchoring action is induced by the interface between the dog-bone parts and the increased confining pressure around the prismatic part; however, its mechanism is not clear yet. 


\subsubsection{Discussion and Applications}

The dog-bone SMA fiber (SF-0.93D) increased bond strength, and the shape memory effect of the SF-0.93H fiber also showed a greater pullout force than that of the plain cold-drawn fiber of the SF- 0.93 . The dog-bone shaped fibers can be manufactured easily and are adequate for mass production. However, activation of the shape memory effect of the SMA fibers embedded in concrete structures is not easy. The heating method used in this study is not applicable to real structures. Direct heating using a live flame is not effective, either, since a large part of the heating energy is absorbed by the concrete. Previous studies used electronic resistance to heat embedded SMA bars (H. Li et al., 2006; L. Li et al., 2007); in such cases, the SMA bars should be continuous. However, the SMA fibers are distributed in concrete discontinuously. Thus, applications of the SF-0.93H and SF-0.93DH fibers are restricted, and a further study is needed to find a way to heat SMA fibers embedded in concrete.

The SMA fibers can be used for crack closing and curing of concrete beams. When cracks develop due to vertical loading on a concrete beam, fire can heat the SMA fibers directly through the cracks. Then, the shape memory effect is activated and, thus, recovery stress develops in the fibers. This stress can close a crack. If adhesive such as epoxy is applied in the crack, the concrete may recover its tensile strength after crack closing.

As illustrated in Figure 6, the cold-drawn NiTi SMAs show stress- relaxation with decreasing temperature after inducing recovery stress with high temperature (Choi et al., 2010b). For crack-repairing, the high recovery stress would work to close a crack, and, then, after the repairing, the stress would decrease. In the case, the decrement of the stress would not be a critical problem since the crack-surfaces are bonded by adhesive and tensile resistance would provide by the bond. However, if the SMA fibers were used for introducing prestressing stress in concrete beams, the stress relaxation would reduce prestressed stress that is working on concrete. Thus, in the case, the stress relaxation of the SMA fibers should be considered in designing concrete beams. Relatively low Young's modulus and high price of NiTi SMA compared with steel are critical problems of the SMA applications for civil structures. Recently, Fe-based SMAs have been developed with high Young's modulus and low price compared with NiTi SMA (Czaderski et al., 2014; Koster et al., 2015). In addition, Fe-based SMAs do not show stress relaxation due to decreasing temperature. Thus, a further study is needed to develop SMA fibers that are made of Fe-based SMA, and mass uses of SMA fibers for civil structures could be possible if Fe-based SMA fibers are developed.

Bond resistance of the SF-0.93H SMA fiber increased comparing with the unheated SMA fiber because of bulging of the fiber due to the shape memory effect. The bulged shape of the heated SMA fibers is not changed even with cooling temperature. Moreover, the bond resistance depends on the shape and friction of SMA fibers and, thus, recovery stress relaxation of SMA fibers do not effect on the bond resistance.

\section{A Pilot Test of a Beam'S Crack-Closing Using SMA Fibers}

The same NiTi SMA wires with a diameter of $1.0 \mathrm{~mm}$ in the above section were prepared for a crack-closing test of a beam. In this test, the SMA wires were elongated by cold-drawing, and their diameter was reduced to $0.965 \mathrm{~mm}$. Then, they were cut with a length of $30 \mathrm{~mm}$ to embed in a mortar beam. A beam with a length of $160 \mathrm{~mm}$ and a width and height of $40 \mathrm{~mm}$ was made of mortar that has a compressive strength of $93 \mathrm{MPa}$. Five SMA fibers were placed at the center and $5 \mathrm{~mm}$ above the bottom of a beam. An artificial notch with $1 \mathrm{~mm}$ width and $10 \mathrm{~mm}$ depth was placed at the bottom center (see Figure 12). The first fiber was placed $6 \mathrm{~mm}$ from the side surface, and the distance between fibers was $28 \mathrm{~mm}$.
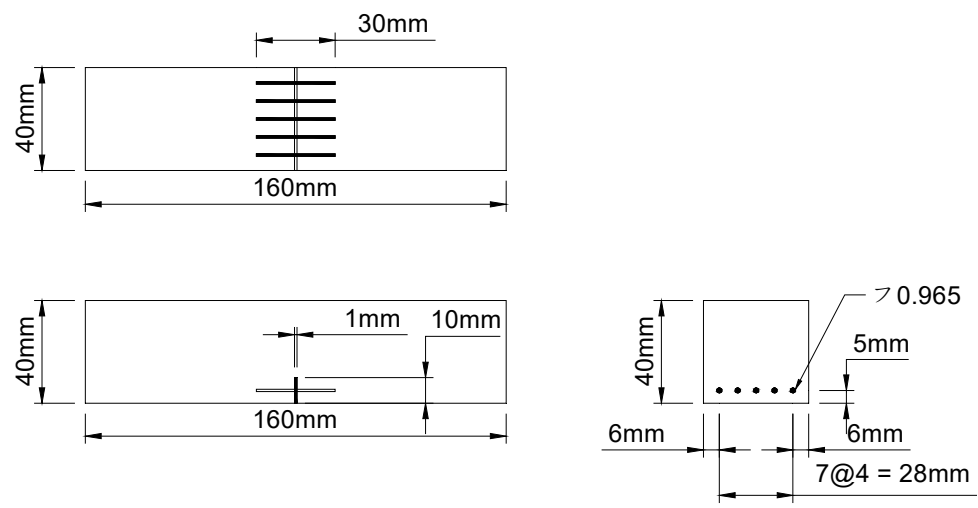

Figure 12. Dimension of a beam specimen and location of SMA fibers 
Three-point bending test was conducted to generate a crack passing through the embedded SMA fibers. After cracking in the beam, the SMA fibers were heated by fire flame. This process increased the temperature of the SMA fiber and induced shape memory effect of the SMA fibers. Recovery stress of the SMA fiber due to the shape memory effect worked to close the open crack, and the bond of the fiber provided anchoring resistance to prevent a slip of the fiber. Figure 13 shows an open crack, heating, and a closed crack in the beam. During the process, a crack-width was measured using a magnifying camera. The crack-width was reduced from $0.58 \mathrm{~mm}$ to $0.29 \mathrm{~mm}$ by closing action of the SMA fibers. More details and experimental results related to the tests will be published in another paper.

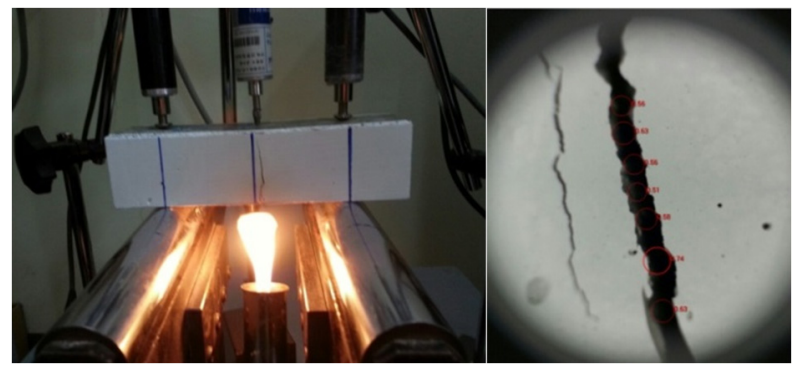

(a) Open crack (width $=0.60 \mathrm{~mm}$ ) and heating SMA fibers

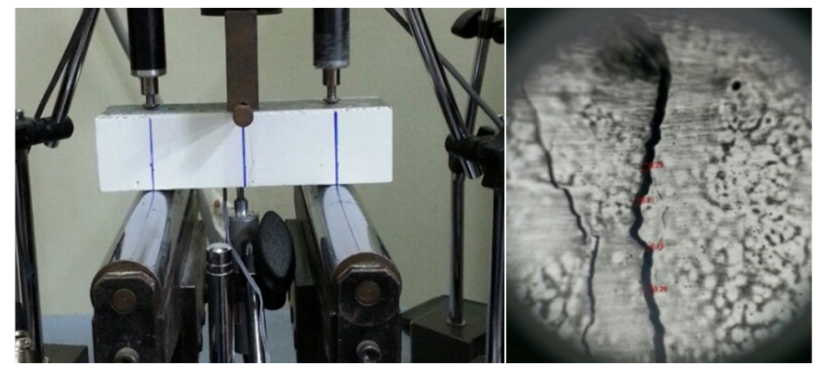

(b) Closing action and closed crack (width $=0.22 \mathrm{~mm}$ )

Figure 13. Crack-closing test

\section{Conclusions}

This study proposed new SMA fibers without hooked ends for mortar or concrete; fibers were manufactured using cold-drawn SMA wires. The cold drawing method is much more practical than direct tension to introduce prestrain into SMA wires and is an adequate method for mass production. However, the cold-drawn SMA wires did not recover all area reduction due to the shape memory effect; on the other hand, the direct tensioned SMA wires recovered all area reduction. The recovered diameters were 0.018 and 0.024 for the 0.93 and $0.965 \mathrm{~mm}$ cold-drawn SMA wires. This indicates that the greater area reduction by cold drawing did not produce greater diameter recovery. Thus, a study is needed to determine an optimized cold drawing process for SMA fibers.

This study illustrates that diameter bulging of prestrained SMA fibers in mortar due to heating generated additional confining pressure around the fibers and increased the pullout force by increasing frictional resistance. This study also assessed the developed confining pressure by adopting the frictional coefficient between the SMA fiber and the mortar. The dog-bone shaped SMA fibers provided additional anchoring action to increase pullout force. The dog-bone shaped SMA fibers showed hardening behavior in the pullout tests, which phenomenon is not found in the heated SMA fibers. When dog-bone shaped SMA fibers were heated inside mortar, they showed tremendously hardening in pullout force after the bond-slip. The maximum pullout force of the dog-bone shaped fibers with heating was twice more than that of the prismatic fibers with heating or the dog-bone shaped fibers without heating. The behavior of the dog-bone shaped fiber with heating is not a linear combination of the behaviors of the prismatic fibers with heating and the dog-bone shaped fibers. It is conjectured that there is an interaction between anchoring action of the end bulging parts and the increased confining pressure around the prismatic part due to the heating. Finally, this study introduced an example applying SMA fibers to close and cure cracks developed in concrete beams including an experimental result.

\section{Acknowledgments}

This work was supported by Core-Technology for Clean Thermal Power Plant of the Korea Institute of Energy Technology Evaluation and Planning (KETEP) grant funded by the Korea government Ministry of Trade, Industry and Energy (No. 20151120100030).

\section{References}

Choi, E., Nam, T. H., \& Cho, B. S. (2005). A new concept of isolation bearing for highway steel bridges using shape memory alloys. Canadian Journal of Civil Engineering, 32(5), 957-67. http://dx.doi.org/10.1139/ 105-049 
Choi, E., Nam, T. H., Cho, S. C., Chung, Y. S., \& Park, T. (2008). The behavior of concrete cylinders confined by shape memory alloy wires. Smart Materials and Structures, 17, 065032. http://dx.doi.org/10.1088/09641726/17/6/065032

Choi, E., Park, J., Yoon, S. J., Choi, D. H., \& Park, C. (2010a). Comparison of seismic performance of three restrainers for multiple-span bridges using fragility analysis. Nonlinear Dynamics, 61(2), 83-99. http://dx.doi.org/10.1007/s11071-009-9633-6

Choi, C., Cho, S. C., Hu, J. W., Park, T., \& Chung, Y. S. (2010b). Recovery and residual stress of SMA wires and applications for concrete structures. Smart Materials and Structures, 19, 094013. http://dx.doi.org/10.1088/ 0964-1726/19/9/094013

Choi, E., Nam, T. H., Yoon, S. J., Cho, S. K., \& Park, J. (2010c). Confining jacketing for concrete cylinders using NiTiNb and NiTi shape meory alloy wires. Smart Materials and Structures, T139, 014058.

Choi, E., Chung, Y. S., Kim, Y. W., \& Kim, J. W. (2010d). Monotonic and cyclic bond behavior of confined concrete using NiTiNb SMA wires. Smart Material and Structures, 20, 075015.

Choi, E., Cho, B. S., Park, J., \& Park, K. (2011). Inducing recovery stress if NiTiNb SMA wires using heat of hydration for confining concrete. Journal of Intelligent Material Systems and Structures, 22(17), 1949-57. http://dx.doi.org/10.1177/1045389X11420587

Czaderski, C., Shahverdi, M., Bronnimann, R., Leinenbach, C., \& Motavalli, M. (2014). Feasibility of iron-based shape memory alloy strips for prestressed strengthening of concrete structures. Construction and Building Materials, 56, 94-105. http://dx.doi.org/10.1016/j.conbuildmat.2014.01.069

DesRoches, R., \& Delemont, M. (2002). Seismic retrofit of simply supported bridges using shape memory alloys. Engineering Structures, 24, 325-32. http://dx.doi.org/10.1016/S0141-0296(01)00098-0

Dolce, M. Cardone, D., \& Marmetto, R. (2000). Implementation and testing of passive control devices based on shape memory alloys. Earthquake Engineering and Structural Dynamics, 29, 945. http://dx.doi.org/10.1002/1096-9845(200007)29:7\%3C945::AID-EQE958\%3E3.0.CO;2-

Gall, K., Tyber, J., Wilkesanders, G., Robertson, S. W., Ritchie, R. O., \& Maier, H. J. (2008). Effect of microstructure on the fatigue of hot-rolled and cold-drawn NiTi shape memory alloys. Materials Science \& Engineering A, 486(1-2), 389-403. http://dx.doi.org/10.1016/j.msea.2007.11.033

Janke, L., Czaderski, C., Motavalli, M., \& Ruth, J. (2005). Application of shape memory alloys in civil engineering structures-overview, limits and new ideas. Materials and Structures, 38(5), 578-92. http://dx.doi.org/10.1007/BF02479550

Koster, M., Lee, W. J., Schwarzenberger, M., \& Leinenbach, C. (2015). Cyclic deformation and structural fatigue behavior of an Fe-Mn-Si shape memory alloy. Materials Science \& Engineering A, 637, 29-39. http://dx.doi.org/10.1016/j.msea.2015.04.028

Krstulovic-Opara, N., \& Naaman, A. E. (2000). Self-stressing fiber composites. ACI Structural Journal, 97(2), $335-44$

Li, H., Liu, Z., \& Ou, J. (2006). Behavior of a simple concrete beam driven by shape memory alloy wires. Smart Materials and Structures, 15, 1039-46. http://dx.doi.org/10.1088/0964-1726/15/4/017

Li, L., Li, Q., \& Zhang, F. (2007). Behavior of smart concrete beams with embedded shape memory alloy bundles. Journal of Intelligent Material Systems and Structures, 18(10), 1003-14. http://dx.doi.org/10.1177/ 1045389X06071974

Li, H., Liu, Z., \& Ou, J. (2008). Experimental study of a simple reinforced concrete beam temporarily strengthened by SMA wires followed by permanent strengthening with CFRP plates. Engineering Structures, 30(2), 716-23. http://dx.doi.org/10.1016/j.engstruct.2007.05.020

Maji, A. K., \& Negret, I. (1998). Smart prestressing with shape-memory alloy. Journal of Engineering Mechanci, 124(10), 1121-28. http://dx.doi.org/10.1061/(ASCE)0733-9399(1998)124:10(1121)

Moser, K., Bergamini, A., Christen, R., \& Czaderski, C. (2005). Feasibility of concrete prestressed by shape memory alloy short fibers. Materials and Structures, 38(1), 593-600. http://dx.doi.org/10.1007/BF02479551

Ozbulut, O. E., \& Hurlebaus, S. (2010). Evaluation of the performance of a sliding-type base isolation system with a NiTi shape memory alloy device considering temperature effects. Engineering Structures, 32(1), 238-49. http://dx.doi.org/10.1007/BF02479551 
Rabbat, B. G., \& Russell, H. (1985). Friction coefficient of steel on concrete or grout. Journal of Structural Engineering, 111, 505-515. http://dx.doi.org/10.1061/(ASCE)0733-9445(1985)111:3(505)

Saleeb, A.F., Dhakal, B., \& Owusu-Danquah, J. S. (2015a). Assessing the performance characteristics and clinical forces in simulated shape memory bone staple surgical procedure: The significance of SMA material model, Computers in biology and medicine, 62, 185-195. http://dx.doi.org/10.1016/j.compbiomed.2015.04.010

Saleeb, A. F., Dhakal, B., \& Owusu-Danquah, J. S. (2015b). On the role of SMA modeling in simulating NiTinol self-expansion stening surgeries to assess the performance characteristics of mechanical and thermal activation schemes, Journal of the Mechanical behavior of biomedical materials, 42, 43-60. http://dx.doi.org/10.1016/j.jmbbm.2015.04.012

Sawaguchi, T., Kikuchi, T., Ogawa, K., Kajiwara, S., Ikeo, Y., Kojima, M., ... Ogawa, T. (2006). Development of prestressed concrete using Fe-Mn-Si-based shape memory alloys containing NbC. Materials Transactions, 47(3), 580-83. http://dx.doi.org/10.2320/matertrans.47.580

Shajil, N., Srinicasan, S. M., \& Santhanam, M. (2013). Self-centering of shape memory alloy fiber reinforced cement mortar members subjected to strong cyclic loading. Materials and Structures, 46(4), 651-61. http://dx.doi.org/10.1617/s11527-012-9923-1

Sharabash, A. M., \& Andrawes, B. O. (2010). Application of shape memory alloy dampers in the seismic control of cable-stayed bridge. Engineering Structures, 31(2), 607-16. http://dx.doi.org/10.1016/j.engstruct.2008. 11.007

Shin, M., \& Andrawes, B. (2010). Experimental investigation of actively confined concrete using shape memory alloys. Engineering Structures, 32, 656-664. http://dx.doi.org/10.1016/j.engstruct.2009.11.012

Song, G., Mo, Y. L., Oter, K., \& Gu, H. (2006). Health monitoring and rehabilitation of a concrete structure using intelligent materials. Smart Material and Structures, 15, 309. http://dx.doi.org/10.1088/0964-1726/15/2/010

Yang, C. W., DesRoches, R., \& Leon, T. L. (2010). Design and analysis of braced frame with shape memory alloy and energy absorbing hybrid devices. Engineering Structures, 22(2), 498-507. http://dx.doi.org/10.1016/j. engstruct.2009.10.011

\section{Copyrights}

Copyright for this article is retained by the author(s), with first publication rights granted to the journal.

This is an open-access article distributed under the terms and conditions of the Creative Commons Attribution license (http://creativecommons.org/licenses/by/3.0/). 